\title{
Comparative study of feto-maternal outcome in clinical and subclinical hypothyroidism
}

\author{
Monika Gupta $^{1 *}$, Poonam Pandotra ${ }^{1}$, Monika Jindal ${ }^{1}$, Gitanjali Jamwal ${ }^{1}$, \\ SPS Goraya ${ }^{1}$, Vipan Gupta ${ }^{2}$
}

\begin{abstract}
${ }^{1}$ Department of Obstetrics and Gynecology, ${ }^{2}$ Department of ENT, Maharishi Markandeshwer Medical College and Hospital, Kumarhatti, Solan, India
\end{abstract}

Received: 20 February 2017

Accepted: 24 March 2017

\author{
*Correspondence: \\ Dr. Monika Gupta, \\ E-mail: monikajindal@ rocketmail.com
}

Copyright: (C) the author(s), publisher and licensee Medip Academy. This is an open-access article distributed under the terms of the Creative Commons Attribution Non-Commercial License, which permits unrestricted non-commercial use, distribution, and reproduction in any medium, provided the original work is properly cited.

\section{ABSTRACT}

Background: Thyroid diseases are the one of commonest endocrine disorders affecting women of reproductive age group, and hence constitute the commonest endocrine disorder complicating pregnancy. Maternal thyroid function changes during pregnancy and inadequate adaptation to these changes results in thyroid dysfunction. The objective of this study was to determine the prevalence of clinical and subclinical hypothyroidism and to study the fetal and maternal complications associated with hypothyroidism.

Methods: A prospective and observational study undertaken over a period of 2 years from 1st October 2009 onwards. Pregnant women were screened for thyroid dysfunction irrespective of gestational age. Patients were divided into two group; Group I (subclinical hypothyroidism)- all pregnant patients with serum TSH $\geq 3 \mathrm{mu} / 1$ up to $6 \mathrm{mu} / \mathrm{l}$ and normal free T4 levels. Group II (clinical hypothyroidism)- all pregnant patients with serum TSH level $\geq 6$ mu/l OR on thyroxine pre-pregnancy.

Results: In the present study, prevalence of thyroid disorder was $6.22 \%$, subclinical hypothyroidism and clinical hypothyroidism being $3.77 \%$ and $2.45 \%$ respectively. In subclinical group and clinical group, we found, preeclampsia, preterm labour, first trimester abortions and oligohydramnios in $13.75 \%$ versus $19.23 \%, 13.75 \%$ versus $36.54 \%$, $11.25 \%$ versus $11.53 \%$, and $16.25 \%$ versus $23.02 \%$ respectively. Subclinical hypothyroidism was more prevalent and hidden leading to the poor obstetrical outcome and fetal complications like low birth weight, prematurity and intrauterine growth restriction. There was higher incidence of caesarean deliveries in both groups more in clinical hypothyroid cases.

Conclusions: Due to the adverse effect of maternal thyroid disorder on maternal and fetal outcome, timely diagnosis and initiation of treatment of hypothyroid disorders is essential.

Keywords: Clinical, Dysfunction, Hypothyroidism, Outcome, Subclinical

\section{INTRODUCTION}

Thyroid diseases are one of the commonest endocrine disorders affecting women of reproductive age group, and hence constitute the commonest endocrine disorder complicating pregnancy.
Overall, incidence of hypothyroidism in women diagnosed before pregnancy is $1 \%{ }^{1}$ The prevalence of thyroid dysfunction during pregnancy is estimated to be $2-5 \%{ }^{2}$ Prevalence of hypothyroidism in India ranges from $6.47 \%$ $14.3 \% .^{3}$ During pregnancy, incidence of subclinical hypothyroidism ranges from $2-7 \% .^{4}$ 
In North India, there is a high prevalence of hypothyroidism (14.3\%), majority being subclinical in pregnant women during first trimester as shown by Dhanwal et al, and necessitating routine screening. ${ }^{5}$ Maternal and fetal complications have been found to be higher in this population as seen in various studies.

Pregnancy has a significant effect on maternal thyroid physiology. Beta-HCG has a thyrotrophic activity and shares $85 \%$ homology with beta subunit of TSH. As a result of this TSH levels decrease in early pregnancy in comparison to non-pregnant women. ${ }^{6,7}$

Deficiency of iodine causes rise in TSH as it is important substrate for thyroxine synthesis. Foetus is dependent on the mother for production of thyroid hormone for 10-12 weeks of pregnancy. Foetal thyroid begins functioning by the end of first trimester, however foetus is dependent on maternal iodine intake. Thyroid hormones are very essential for foetal brain development. Maintaining Thyroid homeostasis is essential for maternal and foetal wellbeing. 6,7

Probable causes of subclinical hypothyroidism are many and chronic autoimmune thyroiditis (e.g., Hashimoto's disease thyroiditis) with a prevalence of $3-8 \%$ in the general population is said to be the most common cause. ${ }^{8}$ Drugs like lithium, amiodarone, interferon-alpha, interleukin-2, rifampicin, sunitinib and thalidomide, presence of goitrogens in diet is also reported from India as probable causes; micronutrient deficiency such as selenium and iron deficiency may cause hypothyroidism and goiter. ${ }^{9-11}$ Environmental toxins such as pesticides, fluoride, heavy metals may lead to hypothyroid state. High estrogen states (pregnancy - it causes decrease in free T4 level), and chronic stress; both physical as well as mental13 along with other diseases like diabetes (specially type-1) which affect pituitary or hypothalamus are some other causes. ${ }^{12,14}$ Women with family history of hypothyroidism or an autoimmune disease are also at increased risk of developing subclinical hypothyroidism. Radiation therapy used to treat cancers of the head and neck can cause problems with the thyroid gland. ${ }^{15}$ Indications for screening at risk patients include history of thyroid dysfunction or prior thyroid surgery, age $>30$ years, symptoms of thyroid dysfunction or the presence of goiter, thyroid peroxidase antibody (TPOAb) positivity, type 1 diabetes or other autoimmune disorders, history of miscarriage or preterm delivery (RPL), history of head or neck irradiation, family history of thyroid dysfunction, morbid obesity (BMI $\geq 40 \mathrm{~kg} / \mathrm{m} 2$ ), use of amiodarone or lithium, recent administration of iodinated radiologic contrast, history of infertility and residing in an area of known moderate-to-severe iodine insufficiency. ${ }^{16}$ There was no consensus on cut off value of TSH during pregnancy till 2010 and majority of the clinicians were not treating subclinical hypothyroidism. So, we conducted this study to determine the prevalence of clinical and subclinical hypothyroidism in pregnant patients and to compare the fetal and maternal outcome in pregnancies affected by clinical and subclinical hypothyroidism.

\section{METHODS}

A prospective observational study was done at Gian Sagar Medical College and Hospital, Ramnagar over a period of 2 years from 1 st October 2009 onwards. All the pregnant patients having serum thyrotropin (TSH) levels above 3 $\mathrm{mu} / \mathrm{l}$ diagnosed during pregnancy or clinical hypothyroid in pre-pregnancy state; who gave consent, were divided into two groups. Group I included the cases with serum $\mathrm{TSH} \geq 3 \mathrm{mu} / \mathrm{l}$ up to $6 \mathrm{mu} / \mathrm{l}$ and normal free T4 levels as subclinical hypothyroid and group II included all hypothyroid cases on thyroxine pre-pregnancy or those detected during pregnancy having serum $\mathrm{TSH}$ level $\geq 6$ $\mathrm{mu} / \mathrm{l}$. Patients with other pre-pregnancy medical disorders such as chronic hypertension, diabetes mellitus and other autoimmune disorders which can also affect pregnancy outcome were excluded from the study.

Both the groups were monitored in similar way. In both groups, target was to maintain the serum TSH levels $\leq 3$ $\mathrm{mu} / \mathrm{l}$. Dose of thyroxine was adjusted according to the serum TSH levels at different intervals. Data was collected by record analysis regarding patients age, parity, previous obstetric history, associated medical, surgical and obstetric complications, duration of hypothyroidism and treatment, free T4 and TSH levels by chemo-luminescence every 6 weekly and pregnancy outcomes. Data obtained was statically analysed by applying chi square test.

\section{RESULTS}

Total number of patients included in study group was 2122 out of which 132 were detected with hypothyroidism. Out of 132, patients detected with clinical hypothyroidism were 52 and those with subclinical were 80 . Prevalence of hypothyroidism in this study was $6.22 \%$, subclinical and clinical hypothyroidism being $03.77 \%$ and $02.45 \%$ respectively.

Table 1 shows maternal demographic variables. Majority of the women were in 20-30 years age group (group I 85\% versus group II $71.15 \%$ ) and were primigravida (group I $43.75 \%$ versus group II $40.38 \%$ ). In both groups, majority patients were from poor socioeconomic status. Number of booked patients was $58.75 \%$ in subclinical group and $67.30 \%$ in clinical group.

Mode of delivery is depicted in Table 2. In group I, 63.75\% patients delivered vaginally as compared to $48.08 \%$ in group II. Of which preterm vaginal deliveries were $11.25 \%$ in group I and $21.16 \%$ in group II (p value being $0.01)$. Rate of caesarean deliveries was more in group II $(51.92 \%)$ as compared to group I $(36.25 \%)$; of which preterm were more in group II $(13.46 \%)$ as compared to group I $(02.50 \%)$ (p value 0.053$)$. 
Table 1: Demographic profile.

\begin{tabular}{|c|c|c|c|c|c|}
\hline \multirow{2}{*}{ Demographic parameter } & \multicolumn{2}{|c|}{ Subclinical hypothyroidism } & \multicolumn{2}{|c|}{ Clinical hypothyroidism } & \multirow{2}{*}{ p-value } \\
\hline & $(\mathbf{n}=\mathbf{8 0})$ & n $(\%)$ & $(\mathbf{n}=52)$ & n $(\%)$ & \\
\hline \multicolumn{5}{|l|}{ Age (years) } & \multirow{5}{*}{0.110} \\
\hline$<20$ & 05 & 06.25 & 04 & 07.70 & \\
\hline $20-30$ & 68 & 85.00 & 37 & 71.15 & \\
\hline $30-40$ & 07 & 08.75 & 11 & 21.15 & \\
\hline$>40$ & 00 & 00.00 & 00 & 00.00 & \\
\hline \multicolumn{5}{|l|}{ Gravida status } & \multirow{5}{*}{0.481} \\
\hline 1 & 35 & 43.75 & 21 & 40.38 & \\
\hline 2 & 24 & 30.00 & 16 & 30.76 & \\
\hline 3 & 15 & 18.75 & 07 & 13.46 & \\
\hline$\geq 4$ & 06 & 07.50 & 08 & 15.40 & \\
\hline \multicolumn{5}{|l|}{ SES } & \multirow{4}{*}{0.297} \\
\hline Poor & 66 & 82.50 & 39 & 75.00 & \\
\hline Middle & 14 & 17.50 & 13 & 25.00 & \\
\hline Upper & 00 & 00.00 & 00 & 00.00 & \\
\hline \multicolumn{5}{|l|}{ Booking status } & \multirow{3}{*}{0.322} \\
\hline Booked & 47 & 58.75 & 35 & 67.30 & \\
\hline Unbooked & 33 & 41.25 & 17 & 32.70 & \\
\hline
\end{tabular}

* Significant

Table 2: Mode of delivery.

\begin{tabular}{|c|c|c|c|c|c|}
\hline \multirow{2}{*}{ Mode of delivery } & \multicolumn{2}{|c|}{$\begin{array}{l}\text { Sub-clinical } \\
\text { hypothyroidism }\end{array}$} & \multicolumn{2}{|c|}{ Clinical hypothyroidism } & \multirow{2}{*}{ p-value } \\
\hline & $(\mathbf{n}=\mathbf{8 0})$ & (n) $(\%)$ & $(n=52)$ & (n) $(\%)$ & \\
\hline \multicolumn{5}{|l|}{ Vaginal } & \multirow{4}{*}{$0.010^{*}$} \\
\hline Full-term & 42 & 52.50 & 14 & 26.92 & \\
\hline Pre-term & 09 & 11.25 & 11 & 21.16 & \\
\hline Total & 51 & 63.75 & 25 & 48.08 & \\
\hline \multicolumn{5}{|c|}{ Lower segment caesarean section } & \multirow{4}{*}{$0.053 *$} \\
\hline Full-term & 27 & 33.75 & 20 & 38.46 & \\
\hline Pre-term & 02 & 02.50 & 07 & 13.46 & \\
\hline Total & 29 & 36.25 & 27 & 51.92 & \\
\hline
\end{tabular}

Table 3: Maternal complications and hypothyroidism.

\begin{tabular}{|c|c|c|c|c|c|}
\hline \multirow{2}{*}{ Maternal characters } & \multicolumn{2}{|c|}{ Sub-clinical hypothyroidism } & \multicolumn{2}{|c|}{ Clinical hypothyroidism } & \multirow[b]{2}{*}{ p-value } \\
\hline & $(\mathrm{n}=\mathbf{8 0})$ & (n) $(\%)$ & $(n=52)$ & (n) $(\%)$ & \\
\hline Preeclampsia & 11 & 13.75 & 10 & 19.23 & 0.400 \\
\hline Preterm labour & 11 & 13.75 & 19 & 36.54 & $0.002 *$ \\
\hline \multicolumn{5}{|l|}{ H/O Abortions } & \multirow{4}{*}{0.405} \\
\hline 1 Abortion & 08 & 10.00 & 04 & 07.69 & \\
\hline 2 Abortions & 01 & 01.25 & 01 & 01.92 & \\
\hline 3 Abortions & 00 & 00.00 & 01 & 01.92 & \\
\hline \multicolumn{5}{|l|}{ Liquor } & \multirow{3}{*}{0.957} \\
\hline Oligoamnios & 13 & 16.25 & 12 & 23.07 & \\
\hline Polyamnios & 01 & 01.25 & 01 & 01.92 & \\
\hline Antepartum haemorrhage & 01 & 01.25 & 00 & 00.00 & 0.418 \\
\hline Postpartum haemorrhage & 01 & 01.25 & 01 & 01.92 & 0.757 \\
\hline Sepsis & 01 & 01.25 & 00 & 00.00 & 0.418 \\
\hline Anaemia & 31 & 38.75 & 12 & 23.07 & 0.060 \\
\hline
\end{tabular}

* Significant

Table 3 shows the maternal complications in women with hypothyroidism. Women with clinical hypothyroidism had higher incidence of preeclampsia (i.e; $19.23 \%$ in comparison to $13.75 \%$ ) but difference was not statically 
significant. Incidence of preterm labour was $13.75 \%$ in group I as compared to $36.54 \%$ in group II with a significant $\mathrm{p}$ value $<0.002$. History of first trimester abortions was more in group I patients as compared to group II patients. Incidences of oligohydramnios and polyhydramnios were more in group II as compared to group I. Incidences of APH, PPH, and sepsis were not significant. Women with clinical hypothyroidism had lower incidence of anaemia $23.07 \%$ in comparison to $38.75 \%$ of women with subclinical hypothyroidism though was not statistically significant. There was no maternal mortality in any group.
Table 4 shows fetal complications in women like low birth weight, prematurity, congenital malformations, intrauterine growth retardation and intrauterine death. Less than $2 \mathrm{kgs}$ weight was present in $7.69 \%$ patients in group II and $3.75 \%$ in group I. In group II $11.54 \%$ neonates have weight between $2-2.5 \mathrm{kgs}$ and in group I, $07.50 \%$ neonates have weight in this range. Prematurity was seen in $36.52 \%$ in clinical group and $13.75 \%$ in subclinical group with a significant $p$ value of $<0.01$. Incidence of IUGR was more in group II (16.25\% versus $19.23 \%)$.

Table 4: Fetal outcome and hypothyroidism.

\begin{tabular}{|c|c|c|c|c|c|}
\hline \multirow{2}{*}{ Maternal characters } & \multicolumn{2}{|c|}{ Sub-clinical hypothyroidism } & \multicolumn{2}{|c|}{ Clinical hypothyroidism } & \multirow[b]{2}{*}{ p-value } \\
\hline & $(n=80)$ & (n) $(\%)$ & $(n=52)$ & (n) $(\%)$ & \\
\hline \multicolumn{5}{|l|}{ Birth - weight (kg) } & \multirow{5}{*}{0.407} \\
\hline$<2$ & 03 & 03.75 & 04 & 07.69 & \\
\hline $2-2.5$ & 06 & 07.50 & 06 & 11.54 & \\
\hline$\geq 2.5-3.75$ & 69 & 86.25 & 42 & 80.77 & \\
\hline$\geq 3.75$ & 02 & 02.50 & 00 & 00.00 & \\
\hline \multicolumn{5}{|l|}{ Pre-mature (weeks) } & \multirow{4}{*}{$0.007 *$} \\
\hline $26-30$ & 00 & 00.00 & 00 & 00.00 & \\
\hline $30-34$ & 07 & 08.75 & 03 & 05.76 & \\
\hline $34-<37$ & 04 & 05.00 & 16 & 30.76 & \\
\hline Congenital malformations & 00 & 00.00 & 01 & 01.92 & 0.757 \\
\hline $\begin{array}{l}\text { Intra uterine fetal death } \\
\text { (IUFD) }\end{array}$ & 01 & 01.25 & 00 & 00.00 & 0.757 \\
\hline $\begin{array}{l}\text { Intra uterine growth } \\
\text { restriction (IUGR) }\end{array}$ & 13 & 16.25 & 10 & 19.23 & 0.659 \\
\hline
\end{tabular}

\section{DISCUSSION}

There has been a debate for a long time about the upper limit of normal TSH during pregnancy. The guidelines of American thyroid association for the diagnosis and management of thyroid disease during pregnancy and postpartum were given in 2011. As per regulation 14.2 of ATA guidelines, if trimester specific ranges for TSH are not available in the laboratory, the following normal reference ranges are recommended: 1 st trimester -0.1 to $2.5 \mathrm{~m} \mathrm{IU} / \mathrm{L}, 2$ nd trimester -0.2 to $3.0 \mathrm{~m} \mathrm{IU} / \mathrm{L}$ and $3 \mathrm{rd}$ trimester -0.3 to $3.0 \mathrm{~m} \mathrm{IU/L}$.

The prevalence of thyroid disorders in pregnancy and fetomaternal complications in the pregnant women with thyroid disorders varies greatly in different regions and different studies. In our study group, prevalence of hypothyroidism was $6.22 \%$. Prevalence of subclinical hypothyroidism and clinical hypothyroidism was $3.77 \%$ and $2.45 \%$ respectively; which may be lower in our study than other studies because cut off is higher in our study than others. A similar study by Sahu et al showed prevalence of $6.4 \%$, which is comparable to our findings. ${ }^{3}$ In North India, there is a high prevalence of hypothyroidism, majority being subclinical in pregnant women during first trimester as in studies by Dhanwal et al $(14.3 \%)$, and Rajput et al $(26.5 \%)$; necessitating routine screening. 5,17

In present study majority women were in age group of 2030 years in both groups I and II (85\% versus $71.15 \%)$ and primigravidas were (43.75\% versus $40.38 \%$ ). In another study by Pavanganga et al, in 20-30 years age group $93 \%$ versus $95 \%$ women were in subclinical and clinical groups and primigravida were $56 \%$ vs $58 \%$ in both groups. ${ }^{18}$

As per our study, in group I; $63.75 \%$ patients delivered vaginally ( $11.25 \%$ being preterm) as compared to $48.08 \%$ in group II (21.16\% being preterm); p value being 0.010 . Total rate of caesarean deliveries was more $(51.92 \%)$ in group II as compared to group I (33.75\%); with a significant $\mathrm{p}$ value i.e. 0.053. Sharma Partha et al noted that cesarean section was needed in $61.54 \%$ cases of hypothyroidism and vaginal delivery in $25.64 \%$ patients which was similar in our study. ${ }^{19}$ Most common indication for LSCS was intrapartum fetal distress. In another study by Lahoti et al, the rate of vaginal delivery in patients with subclinical hypothyroidism as $64.90 \%$, but caesarean delivery was $25.5 \%$ which is less than our study. ${ }^{20} \mathrm{~A}$ study done by Firdushi begum shows cesarean delivery rate of $34.11 \%$ in hypothyroid patients which is also lesser. ${ }^{21}$ 
In subclinical and clinical hypothyroidism groups, prevalence of preeclampsia was $13.75 \%$ versus $19.23 \%$, preterm labour was $13.75 \%$ versus $36.54 \%$ ( $\mathrm{p}$ value being significant), abortions were $11.25 \%$ versus $11.53 \%$ and oligohydramnios was (16.25 versus $23.02 \%$ ) in our study. Sahu $\mathrm{M}$ et al and Leung et al reported PE in $20.7 \%$ and $22 \%$ respectively in clinical hypothyroidism, which are comparable to present study. ${ }^{3,22}$ Sahu $\mathrm{M}$ et al reported preterm delivery in lesser as $4.7 \%$. In another study by Sarladevi et al, overt hypothyroidism in pregnancy was associated with preeclampsia in $14.28 \%$, preterm delivery in $10.71 \%$, and abortions in $7.14 \% .^{3,23}$

In subclinical hypothyroid patients, Sahu MT et al and Saraladevi et al reported preeclampsia in lesser patients as $9.8 \%$ and $9.37 \%$ patients respectively but Leung et al reported the incidence of pre-eclampsia and preterm labour as $15 \%$ and $9 \%$ respectively which is comparable to our study. $3,22,23$ Preterm delivery was reported to be $10.3 \%$ and $7.81 \%$ respectively in both these studies which is again less. Saraladevi et al, also reported the association with abruption in $1.56 \%$ and abortions in $4.68 \% .^{23}$ Studies of Wang et al and Green S showed significant increase in the risk of preterm delivery in women with subclinical hypothyroidism. ${ }^{24,25}$

According to WHO estimates, up to $56 \%$ of all women living in developing countries are anaemic. ${ }^{26}$ In our study, $23.07 \%$ cases had anaemia in clinical hypothyroid group and $38.75 \%$ in subclinical group. Agrawal $U$ et al found $19.09 \%$ patients having anaemia. ${ }^{27}$ It has been suggested that nutritional deficiencies are known to develop in hypothyroidism; the most recognized one is iron deficiency. ${ }^{28}$

As per our observations, low birth weight (less than 2.5 $\mathrm{kgs}$ ) was seen in $11.25 \%$ in group I and $19.22 \%$ patients in group II. Saraladevi et al showed that subclinical and clinical hypothyroidism were associated with low birth weight in $4.68 \%$ and $10.71 \%$ cases respectively (much lower than our study) whereas a study by Leung et al shows low birth weight in $22 \%$ in clinical hypothyroidism cases as in our study. ${ }^{22,23}$ Abolovich et al also reported lower incidence of low birth weight as $6 \%$ in clinical group. ${ }^{29}$

Intra uterine growth restriction was present in $19.23 \%$ in clinical hypoyhyroidism and $16.25 \%$ in subclinical group. Studies of Idris et al, Sahu et al and Miao L et al showed increased prevalence of growth restriction in women with subclinical hypothyroidism. ${ }^{3,30,31}$ Studies of Saki F et al showed $13.7 \%$ of women with subclinical hypothyroidism had IUGR. ${ }^{32}$ In study by Saraladevi et al, clinical hypothyroidism in pregnancy was associated with IUGR in $10.71 \%$ patients. ${ }^{23}$

Several studies have also reported still births; like Sahu M et al $(2.9 \%)$ Leung et al, (4\%) Abolovich et al (3\%), Saraladevi et al $(3.57 \%)$ in clinical hypothyroidism but no still birth was seen in both the groups in present study. $3,22,23,29$

Increased rate of most of the maternal and fetal complications in subclinical group in present study can be explained by the significant number of unbooked patients $(41.25 \%)$. Majority of the physicians were not treating subclinical hypothyroidism and there was lack of universal screening and treatment guidelines for hypothyroidism in pregnancy during study period.

In pregnant women, larger doses of levothyroxine are needed due to rapid rise in TBG levels resulting from physiological rise of estrogen. Women who are already on thyroxine before pregnancy need to increase the daily dosage on an average, by $30-50 \%$ above the preconception dosage. During pregnancy, full replacement dose of thyroxine is around $2-2.4 \mathrm{mcgm} / \mathrm{kg} / \mathrm{day}$. In this study, women with clinical hypothyroidism had complications despite on treatment with levothyroxine.

\section{CONCLUSION}

Thyroid dysfunction during pregnancy is associated with higher incidence of adverse fetomaternal outcome. Thus, increased awareness of associated maternal and fetal complications, timely diagnosis and initiation of treatment of hypothyroid disorders is essential to ensure a healthy mother giving birth to a healthy baby in every single pregnancy.

\section{Funding: No funding sources}

Conflict of interest: None declared

Ethical approval: The study was approved by the Institutional Ethics Committee

\section{REFERENCES}

1. Studd J. Progress in Obstetrics and Gynaecology, vol 15. London. Churchill Livingstone; 2003:75-101.

2. Unnikrishnan AG, Kalra S, Sahay RK, Bantwal G, John $\mathrm{M}$, Tewari N, et al. Prevalence of hypothyroidism in adults: an epidemiological study in eight cities of India: Indian $\mathbf{J}$ of endocrinology and metabolism. 2013;17(4):647-52.

3. Sahu MT, Das V, Mittal S. Overt and subclinical thyroid dysfunction among Indian pregnant women and its effect on maternal and fetal outcome. Arc Gynaecol Obstet. 2010;281(2):215-20.

4. Ravanbod M, Asadipooya K, Kalantarhormozi M, Nabipour I, Omrani GR. Treatment of iron deficiency anaemia in patients with subclinical hypothyroidism. Am J Med. 2013;126(5):420-4.

5. Dhanwal DK, Prasad S, Agarwal AK, Dixit V, Banerjee AK. High prevalence of subclinical hypothyroidism during first trimester of pregnancy in North India. Indian J Endocrinol Metab. 2013;17(2):281-4.

6. El Baba KA, Azar ST. Thyroid dysfunction in pregnancy: Intern J Intern Med. 2012;5:227-30. 
7. Cignini P, Cafa EV, et al. Thyroid physiology and common diseases in pregnancy: review literature. $\mathrm{J}$ Prenat Med. 2012;6(4):64-71.

8. Fatourechi V. Subclinical hypothyroidism: an update for primary care physicians. Mayo Clin Proc. 2009;84(1):65-71.

9. Chakera AJ, Pearce SH, Vaidya B. Treatment for primary hypothyroidism: current approaches and future possibilities. Drug Design Devel Ther. 2012;6:1-11.

10. Marwaha RK, Tandon N, Gupta N, Karak AK, Verma $\mathrm{K}$, Kochupillai N. Residual goitre in the postiodization phase: iodine status, thiocyanate exposure and autoimmunity. Clin Endocrinol (Oxf). 2003;59(6):67281.

11. Das S, Bhansali A, Dutta P, Aggarwal A, Bansal MP, Garg D, et al. Persistence of goitre in the post-iodization phase: micronutrient deficiency or thyroid autoimmunity? Indian J Med Res. 2011;133:103-9.

12. Steingold KA, Matt DW, DeZiegler D, Sealey JE, Fratkin M, Reznikov S. Comparison of transdermal to oral estradiolwomen with premature ovarian failure. J Clin Endocrinol Metab. 1991;73(2):275-80.

13. Sapolsky RM, Krey LC, McEwen BS. The neuroendocrinology of stress and aging: the glucocorticoid cascade hypothesis. Endocr Rev. 1986;7(3):284-301.

14. Ongphiphadhanakul B, Fang SL, Tang KT, Patwardhan NA, Braverman LE. Tumor necrosis factor-alpha decreases thyrotropin-induced 5'-deiodinase activity in FRTL-5 thyroid cells. Eur J Endocrinol. 1994;130(5):502-7.

15. Rivkees SA. Pediatric Graves' disease: controversies in management. Horm Res Paediatr. 2010;74(5):305-11.

16. Stagnaro-Green A, Abalovich M, Alexander E, Azizi F, Mestman J, Negro R, et al. American thyroid association taskforce on thyroid disease during pregnancy and postpartum. Guidelines of the American thyroid association for the diagnosis and management of thyroid disease during pregnancy and postpartum. Thyroid. 2011;21(10):1081-125.

17. Rajput R, Goel V, Nanda S, Rajput M, Seth . Prevalence of thyroid dysfunction among women during the first trimester of pregnancy at a tertiary care hospital in Haryana. Ind J Endocrinol Metab. 2015;19(3):416-9.

18. Pavanaganga A, Rekha BR, Sailakshmi MPA, Nagarathnamma R. Observational study of subclinical hypothyroidism in pregnancy. Indian J Obst Gynaecol Res. 2015;2(4):255.

19. Sharma P, Partha M, Amitabha A. Hypothyroidism in pregnancy. J Obstet Gynecol India. 2007;57(4):331-4.
20. Lahoti SK, Toppo L Subclinical hypothyroidism and pregnancy outcomes. Ann Int Med Den Res. 2015;1(3):324-6.

21. Begum F. Thyroid dysfunction and pregnancy outcome. IOSR Journal of Dental and Medical Sciences (IOSRJDMS). 2016;15(9):07-10.

22. Leung AS, Millar LK, Koonings PP, Montoro M, Mestman JH. Perinatal outcomes in hypothyroid pregnancies. Obstet Gynecol. 1993;81(3):349-53.

23. Saraladevi R, Nirmala Kumari T, Shreen B, Usha Rani $\mathrm{V}$. Prevalence of thyroid disorder in pregnancy and pregnancy outcome. IAIM. 2016;3(3):1-11.

24. Wang S, et al. Clinical or subclinical hypothyroidism and thyroid antibodies before 20 weeks of pregnancy and risk of Preterm birth: a systematic review. Zhonghua Fu Chan Za Zi. 2014;49(11):816-22.

25. Green AS, Maternal thyroid disease and preterm delivery. J Clin Endocrinol Metab. 2009;94(1):21-5.

26. World Health Organization. The prevalence of anemia in women: a tabulation of Available Information; second edition. Geneva: WHO; 1992.

27. Agrawal U, Shrivastava P, Shrivastava S. Hypothyroidism and anemia in pregnancy. Int $\mathbf{J}$ Adv Med. 2016;3:851-4.

28. Fein HG, Rivlin RS. Anemia in thyroid disease. The Medical Clinics of North America. WB Saunders Co., Philipines; 1975:59.

29. Abalovich M, Gutierrez S, Alcaraz G, Maccallini G, Garcia A, Levalle O. Overt and subclinical hypothyroidism complicating pregnancy. Thyro. 2002; $12: 63-6$

30. Idris I, Srinivasan R, Simm A. Maternal hypothyroidism in early and late gestation: effects on neonatal and obstetric outcome. Clin Endocrinol (Oxf). 2005;63:5605 .

31. Chen LM, Du WJ, Dai J, Zhang Q, Si GX, Yang H, et al. Effects of subclinical hypothyroidism on maternal and perinatal outcomes during pregnancy: a single cohort study of Chinese population. PLoS One. 2014;9(10):e109364

32. Saki F, Dabbaghmanesh MH, Ghaemi SZ, Forouhari S, Ranjbar Omrani G, Bakhshayeshkaram M. Thyroid function in pregnancy and its influence on maternal and fetal outcomes. Int Endocrinol Metabol. 2014;12(13):e19378

Cite this article as: Gupta $M$, Pandotra $P$, Jindal $M$, Jamwal G, Goraya SPS, Gupta V. Comparative study of feto-maternal outcome in clinical and subclinical hypothyroidism. Int J Reprod Contracept Obstet Gynecol 2017;6:1909-14. 